\title{
Experimental model for learning in vascular surgery and microsurgery: esophagus and trachea of chicken ${ }^{1}$
}

\author{
Modelo para o aprendizado experimental em cirurgia e microcirurgia vascular: esôfago e \\ traquéia de frango
}

\author{
Rosi Aparecida Nunes Achar ${ }^{\mathrm{I}}$, Pedro Alexandre Martinez Lozano ${ }^{\mathrm{II}}$, Bruna Nunes Achar ${ }^{\mathrm{II}}$, Gerson Vilhena Pereira Filho ${ }^{\mathrm{IV}}$, \\ Eduardo Acharv \\ ${ }^{1}$ Research performed at the Laboratory of Experimental Surgery, University of Sao Paulo City (UNICID), Brazil. \\ ${ }^{I}$ Assistant Professor, Experimental Surgery, UNICID, Sao Paulo-SP, Brazil. Conception, design intellectual, scientific content of the study and \\ manuscript writing. \\ ${ }^{\text {II }}$ Assistant Professor, Experimental Surgery, UNICID, Sao Paulo-SP, Brazil. Guidelines and surgical procedures, acquisition of data. \\ III Graduate student, UNICID, Sao Paulo-SP, Brazil. Helped with technical procedures, collection of study informations. \\ ${ }^{\text {IV }} \mathrm{PhD}$, Assistant Professor, Experimental Surgery, UNICID, Sao Paulo-SP, Brazil. Responsible for intellectual and scientific content of the study, \\ manuscript writing. \\ ${ }^{\mathrm{v}} \mathrm{PhD}$, Assistant Professor, Experimental Surgery, UNICID, Sao Paulo-SP, Brazil. Supervised all phases of the study and manuscript writing.
}

\begin{abstract}
Purpose: This paper proposes a model of training surgical skills using vascular anastomosis in an animal model that simulates the size, consistency and resistance arteries and veins, to use it to chicken trachea and esophagus, respectively. Methods: We used chicken necks where the esophagus and trachea were dissected and after preparation were followed every step of the procedure of vascular anastomosis. The flow of the anastomosis was confirmed by direct observation and testing of filling (empty-and-refill test) immediately after the anastomosis. Results: All samples proved to be viable by the criteria described above. Conclusion: For the first time presents an interesting experimental model used to train vascular sutures, because it is endowed with all the necessary requirements for the learning of experimental vascular surgery.

Key words: Anastomosis, Surgical. Microsurgery. Sutures. Esophagus. Trachea.

\section{RESUMO}

Objetivo: O presente trabalho propõe um modelo de treinamento de habilidades cirúrgicas em anastomoses vasculares utilizando um modelo que simula o calibre, a consistência e a resistência arterial e venosa, utilizando-se para isto a traquéia e esôfago de frango, respectivamente. Métodos: Foram utilizados pescoços de frango, onde foram dissecados esôfago e traquéia e após preparo foram seguidos todos os passos do procedimento da anastomose vascular. O fluxo das anastomoses foi comprovado por observação direta e teste de enchimento imediatamente após as anastomoses. Resultados: Todas as amostras mostraram-se viáveis pelos critérios acima descritos. Conclusão: Pela primeira vez apresenta-se um modelo experimental interessante que serve para treinar suturas vasculares, pois é dotado de todos os requisitos necessários para o aprendizado da cirurgia vascular experimental.
\end{abstract}

Descritores: Anastomose Cirúrgica. Microcirurgia. Suturas. Esôfago. Traquéia. 


\section{Introduction}

Mastering the technique of vascular anastomosis is a prerequisite for the realization of reconstructive surgical procedures, such as free flaps and reimplanted ${ }^{1}$.

The training of vascular surgical technique goes through several stages before its clinical use, among these are: training in rubber gloves, small animals (rats, rabbits and guinea pigs) and medium-sized dog and pig as ${ }^{2-4}$. However, there was a training model that simulates the size, strength and texture of arteries and veins, with no need for animal sacrifice, or increased costs.

The transition between the experimental and the practical clinical application requires training which can simulate all stages of the surgery in humans. Enabling the doctor to perform surgery is dependent on training to develop their motor skills. A simple theoretical presentation enables him not to perform surgical procedures. The use of animal models is the main opponent to the public and the students themselves that question the sacrificial animal in large numbers for training. Since the beginning of medicine, various ethical, bioethical, philosophical and even religious emerged in opposition to using animals in research $^{5}$. After World War II and as a result of the atrocities even against the man in the concentration camps, the society was manifested and the Code of Nuremberg (1947) determined that the trial in man should have as a substrate for animal research, a position substantiated by Helsinki Declaration of 1975. Society and animal rights groups protested and in Brazil the express terms of Law No. 9.605/98, in the discipline offered by $\S 1$ of Article 32 are as follows: "Section 32. Engaging in acts of abuse, injure, maim wildlife, domestic or domesticated, native or exotic Penalty - detention of 3 (three) months to 1 (one) year and a fine. $\S 1$ incur the same penalties as those performing painful or cruel experiments on animals alive, even for educational or scientific purposes, when there are alternative resources. "The Law is clear and the concept of humanization should guide the entire production of knowledge's Own scientific and technological development enables man with sufficient conditions for giving up only experiments in living cells. Proceeds are then routinely use of inert material for training, but this does not provide the surgeon to perceive the quality of strength, texture, thickness, or even to be able to test whether the anastomosis does not present problems with bleeding. Training in anima nobile is to expose the patient to injury and medical error ${ }^{6,7}$. This raises the need for balance, in which the researcher the possibility of exhausting all alternatives ${ }^{5,8,9}$, including the use of animals already dead, only as a last step, make use of live animals, which should be treated with absolute respect in recognition of service to provide, often with their lives, for the development of human knowledge. Working conversely, starting from the experimentation on live animals, is often unacceptable and constitutes a crime ${ }^{10-13}$. This paper aims to describe an experimental model that meets these needs.

\section{Methods}

We used chicken necks purchased fresh poultry slaughterhouse. Then proceeded to the careful dissection of both organs(Figure 1)and choiceofmaterials synthesispressure(Figure2)

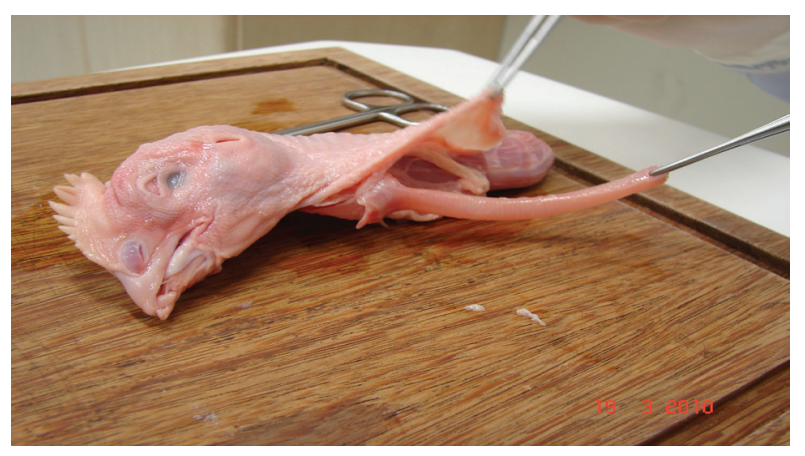

FIGURE 1 - Dissection of trachea and esophagus

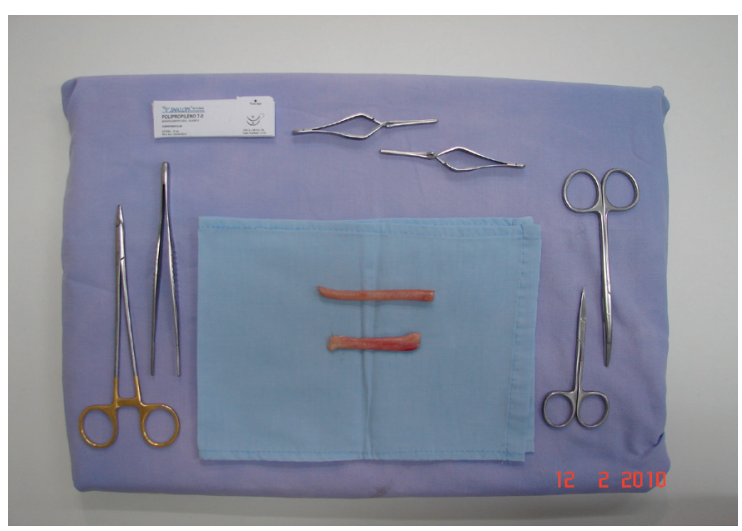

FIGURE 2 - Surgical instruments

With the esophagus and trachea separated from other structures in their cranial and caudal portions, positioning themselves for the clamps and vascular surgery divides up the structures already individualized one at a time, with a straight scissors for microsurgery. The ends are properly washed with saline solution $0.9 \%$ for the removal of mucus that coats the walls and dried with cotton swabs (Figure 3). 


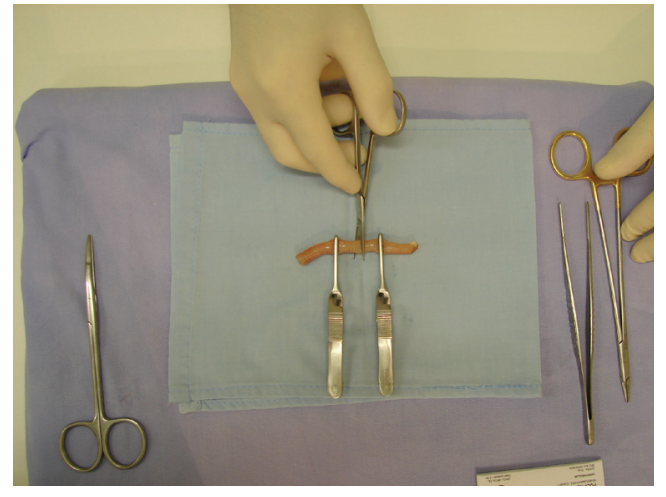

FIGURE 3 - Section of the trachea

It is necessary, then, the practice of using intravenous suture the esophagus and cut resistance and texture of the chicken trachea, simulating arterial suture (Figure 4).

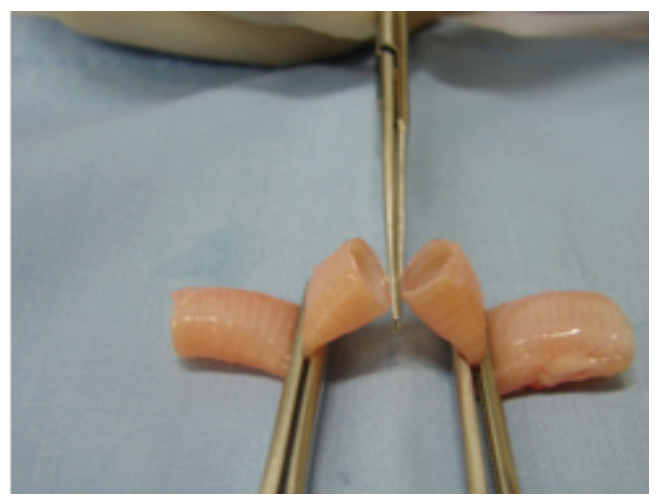

FIGURE 4 - Trachea simulating artery lumen

The simulation must be done carefully, following closely the use of materials and techniques of vascular surgery. This material may be beyond the sutures (Figures 5-9).

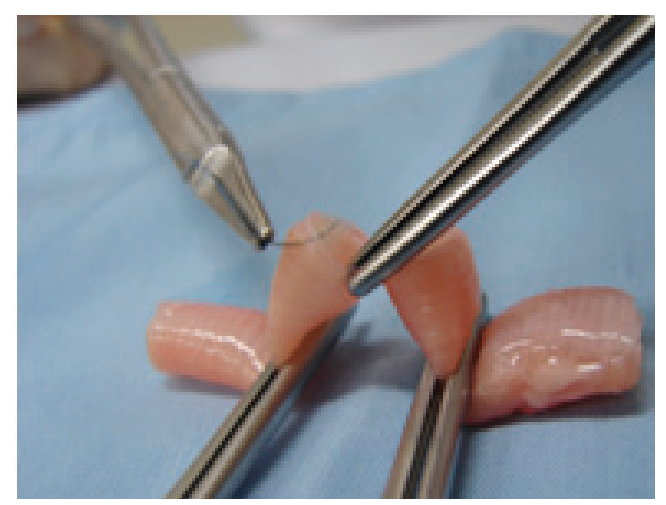

FIGURE 5 - Continuous suture (Step 1)

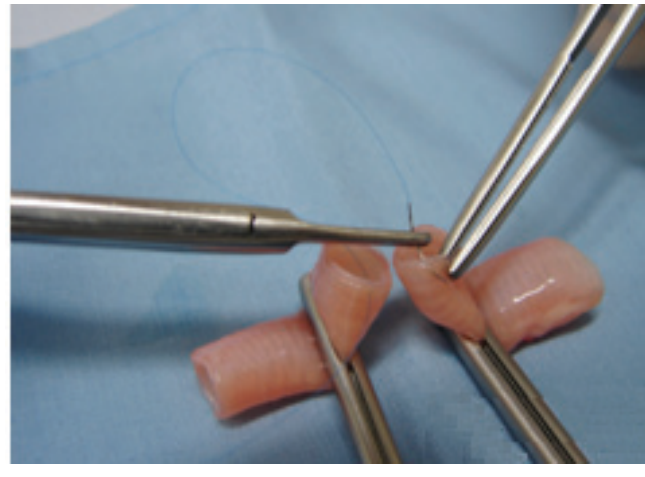

FIGURE 6 - Continuous suture (Step 2)

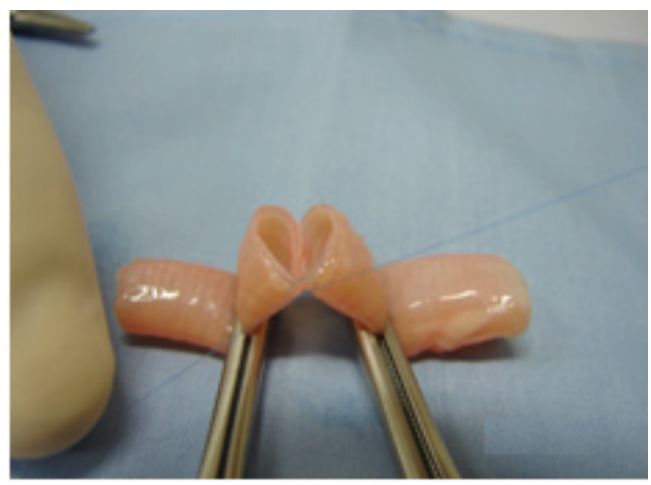

FIGURE 7 - Continuous suture (Step 3)

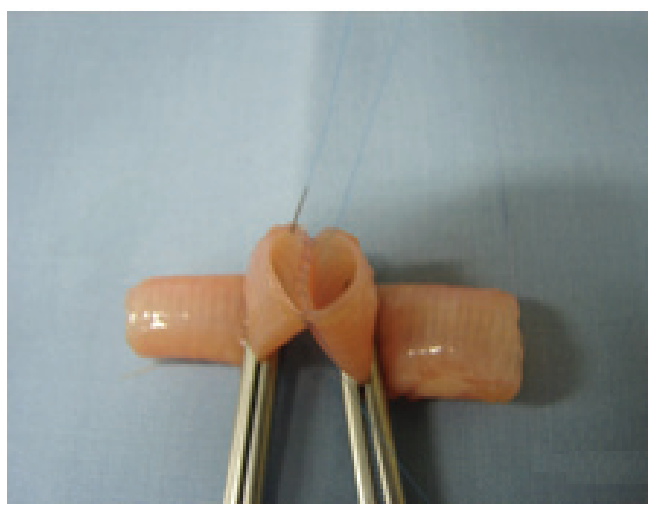

FIGURE 8 - Continuous suture of posterior wall (Step 4)

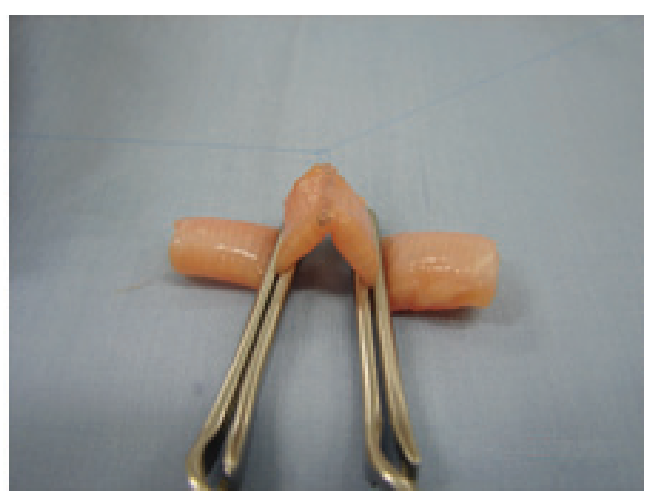

FIGURE 9 - Complete continuous Suture (Step 5) 
Train to separate stitches simple (Figures 10-13) and beyond the suture end-to-end suture and suture of the lateral edges of different sizes. Staying connected, esophagus and trachea to the other structures of the neck can train the anastomosis with some difficulty of access, which better simulates the actual surgical field. Removing the esophagus and trachea and separating them from the rest of the neck, a length of about $3 \mathrm{~cm}$ training for beginners becomes easier. Training can be done also with finer yarns and the use of magnifiers and microscope. As described, the training can be divided into stages of increasing difficulty for wide and thorough training of the surgeon's skills. Starting up your workout with the structures removed from their inserts, and then keeping them connected with other structures with limited training more realistic. Already trained for different types of sutures (end-terminal, end-to-side, different calibers, sutures, stitches, etc.) surgeons can train using magnifying glass and microscope for greater dexterity skills.

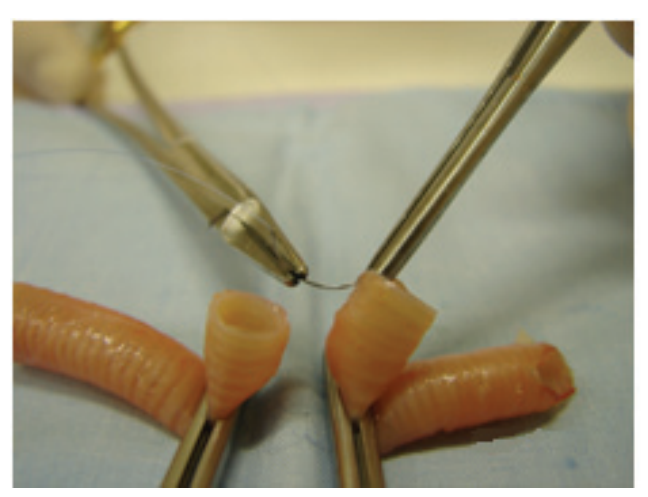

FIGURE 10 - Separate simple suture (Step1)

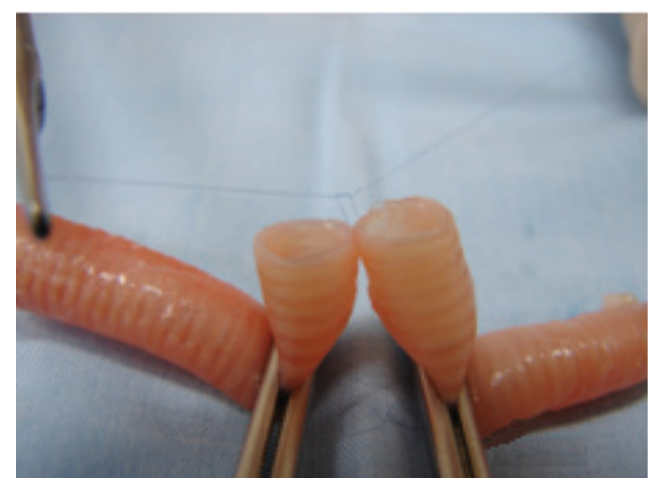

FIGURE 11 - Separate simple suture (Step2)

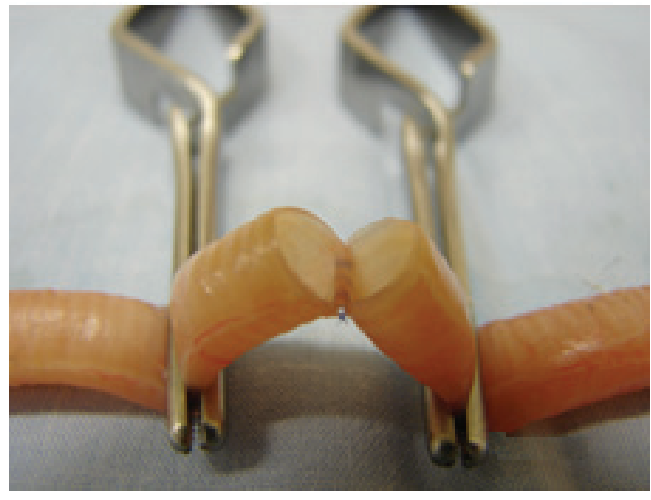

FIGURE 12 - Separate simple suture (Step3)

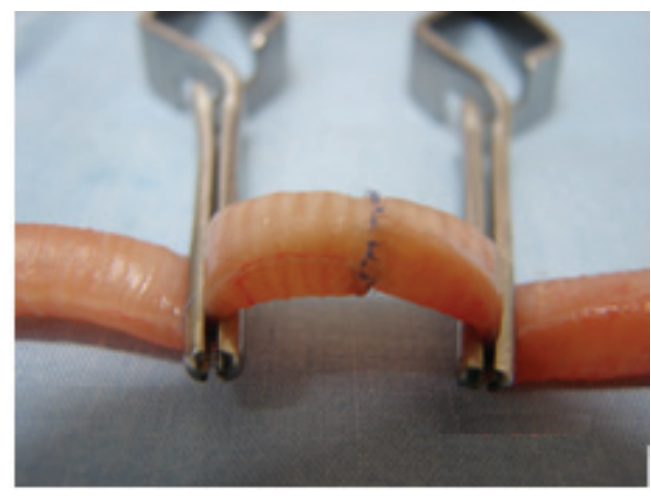

FIGURE 13 - Separate simple suture (Step 4)

\section{Results}

Verification testing of the flow

Keeping the vascular clamp pinching the structure distal to the anastomosis and the other clamp on the proximal portion until about $2 \mathrm{~cm}$ of the suture line, with the aid of $1 \mathrm{ml}$ syringe and needle $8 \times 0.30 \mathrm{~mm}$, iodine is injected under $5 \%$ pressure to evaluate points of "bleeding" (Figures 14 and 15).

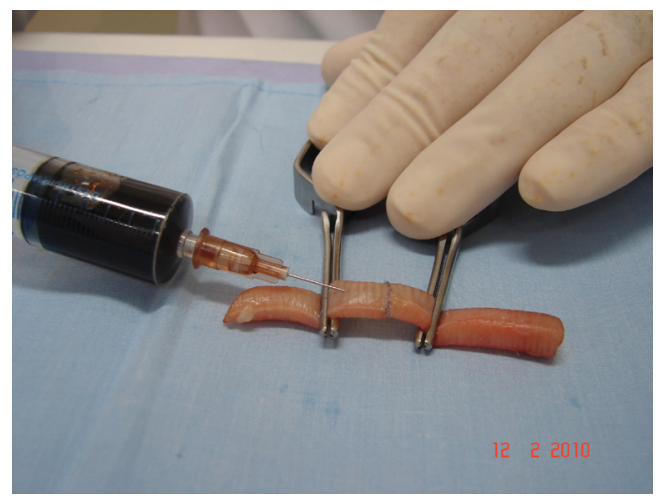

FIGURE 14 - Check for puncture 


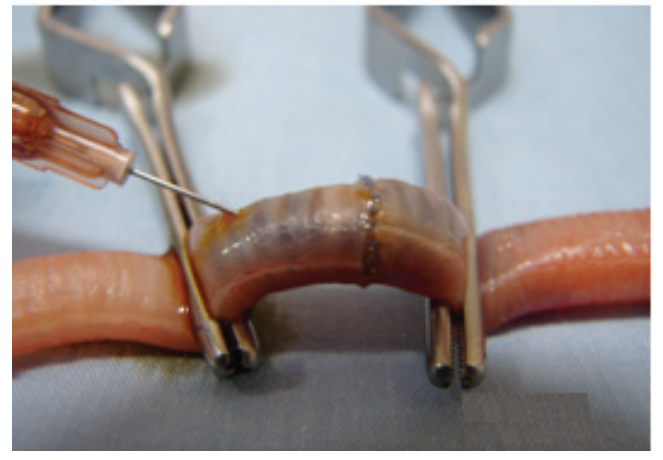

FIGURE 15 - Iodine injection to checking suture

If these points of 'bleeding' occur, should be interpreted as a warning sign and motivate the surgeon to revise the anastomosis.

Visual analysis of the bed vessel is proceeded without major difficulties, simply removing the clamps and releasing the ends, everts the structure and then evaluates whether the suture caused or not, narrowing the caliber of the 'pot', i.e. if there is or not stenosis.

With the training done in stages of increasing degrees of difficulty, the surgeon has developed his skills in all areas: manual dexterity, training in different suture techniques, such as micro vascular and require a new dimension with the need to approach often used magnifying glasses or microscopes, can be a high degree of technical quality, because the skill acquired during training in microsurgery makes the surgeon or surgical residents familiar with suture techniques and vascular reconstruction.

\section{Discussion}

For the exercise of the microsurgical technique is indispensable prior training in inert materials and experimental animals, being advocated by some authors an index greater than $98 \%$ success anastomosis in vessels $0.5 \mathrm{~mm}$ to follow to use it in humans ${ }^{2,17}$.

The training labs are very useful for acquiring new surgical skills or improving skills already acquired, because it works so adjunct to the operating room and recreate similar situations at the hospital ${ }^{14,15}$.

Daniel and Terzis ${ }^{18}$ proposed the use of cadaver vessels for training; however, it becomes necessary to obtain fresh cadavers, which is not always easy to access. This model first described allows the study and basic training in micro vascular, because it can perform both termino-terminal anastomoses, termino-lateral anastomosis between structures with diameters asymmetric.

The use of microsurgical technique should always start at laboratório ${ }^{16}$. The reality view in different dimensions can be worked repeatedly with low cost material, but with greater similarity to the reality than the use of inert materials such as rubber gloves or silicone tubes.

With the graduation of the difficulties, the surgeon is gaining every step skills and honing their skills. Using this model ensures a more appropriate training, which added to the cost of material, meets the ethical and bioethical proposals.

Several factors are causes of failure in micro vascular anastomosis, but many of these factors are abolished if the training is intense and accomplished if the conditions offered for such training are more similar to reality. The comprehensive training is useful for acquiring new surgical skills or improving skills already acquired.

\section{Conclusion}

For the first time presents an interesting experimental model that serves as a tool for those wishing to train vascular sutures, because it is endowed with all the necessary requirements for the learning of experimental vascular surgery.

\section{References}

1. Kallás IE, Kallás AC, E. Callas. Anastomoses arteriais: passado, presente e futuro. Acta Cir Bras. 1999;14(4):221-7.

2. Acland RD. Microsurgery practice manual. St. Louis, Missouri: The C. V. Mosby; 1980.

3. Buncke H, Schultz WP. Total ear reimplantation in the rabbit Utilizing Micro miniature vascular anastomosis. Br J Plast Surg. 1966;19:15-22.

4. Miller CC, Fowler JD, Bowen CV, Chang P. Experimental and clinical free cutaneous transfers in the dog. Microsurgery. 1991;12:113-7.

5. Petroianu A. Ethical aspects in research on animals. Arch Surg. 1996;11:157-64

6. Fagundes DJ, Taha MO. An animal model of disease: choice criteria and animal species in current use. Arch Surg. 2004;19(1):59-65.

7. Schanaider A, Silva PC. The use of experimental animals in surgery. Acta Cir Bras. 2004;19(4):441-7.

8. Hosnuter M, Tosun Z, Savaci N. A nonanimal model for microsurgical training with adventitial stripping. Plast Reconstr Surg. 2000;106(4):958-9.

9. Silva PC. The use of animals in biomedical experimentation. Rev Med Surg. 1997;1:71-9.

10. Bowd AD. Ethics and animal experimentation. Am Psychol. 1980;35:224-5.

11. Britt D. Ethics, committees and ethical animal 
experimentation. Nature. 1984;311:503-6.

12. Rowan AN. Formulation of ethical standards for use of animals in medical research. Toxicol Lett. 1993; 68:63-71.

13. Lazaro da Silva A. Search "in anima nobile". Arch Surg. 1992;7:171-2.

14. Klein I, Steger U, Timmermann W, Thiede A, Gassel HJ. Microsurgical training course for clinicians and Scientists at a German University hospital: a 10-year experience. Microsurgery. 2003;23(5):461-5.

15. Wanzel KR, Madsumoto ED, Stanley JH, Dimitri JA. Teaching technical skills: training on a simple, inexpensive, and portable model. Plast Reconstr Surg. 2002;109(1):258-63. 16. Ostrup L, Fredericson JM. Distant transfers as a free, living bone graft by microvascular anastomosis. Plast Reconstr Surg. 1974;54:274-85.

17. O'Brien B, Morrison W. Reconstructive microsurgery. New York: Churchill Livingstone; 1987.

18. Daniel RK, Terzis JK. Microvascular surgical techniques. In: Daniel RK, Terzis JK. Reconstructive microsurgery. Boston: Little Brown; 1979. p 98-9.

\section{Correspondence:}

Conflict of interest: none

Eduardo Achar Financial source: UNICID

Rua Cesário Galeno, 448/475

03071-000 São Paulo - SP Brasil

Phone: (55 11)2178-1252

eachar@edu.unicid.br

Received: September 20, 2010

Review: November 16, 2010

Accepted: December 14, 2010 